Centre of expertise on child sexual abuse

\title{
A new typology of child sexual abuse offending
}

March 2020

The Centre of expertise on child sexual abuse in collaboration with the Centre for Abuse and Trauma Studies, Middlesex University 


\section{Acknowledgements}

We would like to acknowledge the Centre for Abuse and Trauma Studies at Middlesex University for conducting the underpinning research to develop this new typology of child sexual abuse (CSA) offending. Their research was carried out by a team of experts in the fields of criminology and psychology, specialising in the experiences of offenders, victims and criminal justice agencies tackling CSA. The programme was co-led by Dr Elena Martellozzo (Middlesex University) and Professor Julia Davidson (University of East London), and was project-managed by Dr Jeffrey DeMarco (Middlesex University). Dr Andy Monaghan was the team's researcher. In addition, we would like to thank Professor Michael Seto, who commented on the typology during the first two stages of its development.

We would like to thank Norfolk Constabulary, the Metropolitan Police Service, Sussex Police, West Yorkshire Police and the Lucy Faithfull Foundation for their help in providing case files to support the initial development of the typology, as well as the professionals who took part in focus groups.

Our thanks go also to the CSA Centre's colleagues and partners, especially to members of our Development and Review Panel who reviewed the typology at various stages of its development and gave us feedback. We are also grateful to Saint Mary's Sexual Assault Referral Centre in Manchester for allowing us to conduct further analysis of a dataset which had been anonymised and analysed as part of a previous study, and to the National Organisation for the Treatment of Abusers and Rape Crisis England \& Wales for allowing us to run workshops at their conferences.

\section{About the Centre of expertise on child sexual abuse}

The Centre of expertise on child sexual abuse (CSA Centre) wants children to be able to live free from the threat and harm of sexual abuse. Its aim is to reduce the impact of child sexual abuse through improved prevention and better response.

We are a multi-disciplinary team, funded by the Home Office and hosted by Barnardo's, working closely with key partners from academic institutions, local authorities, health, education, police and the voluntary sector. However, we are independent and will challenge any barriers, assumptions, taboos and ways of working that prevent us from increasing our understanding and improving our approach to child sexual abuse.

To tackle child sexual abuse we must understand its causes, scope, scale and impact. We know a lot about child sexual abuse and have made progress in dealing with it, but there are still many gaps in our knowledge and understanding which limit how effectively the issue is tackled.

Please note that some readers may find the content of this report distressing. You can find information on how to access support on our website at: www.csacentre.org.uk/where-to-get-help/ 


\section{Contents}

Executive summary

$\begin{array}{ll}\text { 1. Introduction } & 7\end{array}$

$\begin{array}{ll}\text { Aim of the work } & 7\end{array}$

$\begin{array}{ll}\text { Background } & 7\end{array}$

Method 8

Limitations $\quad 9$

Definitions 9

2. The typology 11

Child sexual abuse within the family environment 12

Child sexual abuse through trusted relationships outside the family environment

$\begin{array}{ll}\text { Child sexual abuse through an intermediary } & 14\end{array}$

Child sexual abuse through online interaction 15

Child sexual abuse through viewing, sharing or possessing images 16

Child sexual abuse through groups and networks 17

Child sexual abuse arranged and perpetrated for payment 19

Child sexual abuse through a personal connection 20

Child sexual abuse through attack by an unknown person 21

3. Conclusion 22

Appendix 1: Methodology $\quad 24$

Ethics 24

Rationale for the selection of the case files 25

Stage 1: The initial case file analysis 26

Stage 2: Initial testing of the typology 27

Stage 3: Further testing of the typology 29

Stage 4: Review by sector experts 30

$\begin{array}{ll}\text { References } & 31\end{array}$ 


\section{Executive summary}

This report presents a new typology of child sexual abuse (CSA) offending, which has been developed through research led by the Centre for Abuse and Trauma Studies (CATS) at Middlesex University and the Centre of expertise on child sexual abuse (the CSA Centre) over the last 18 months.

The research aimed to develop a typology of CSA offending by focusing on the context of offending and drawing out types that reflect different patterns of offending, rather than by focusing on the characteristics of the perpetrator or the victim. The typology therefore seeks to present a fuller representation of CSA offending, including online and contact abuse, enabling us to view CSA in a new light and making it possible to identify connections between different types of offending that might otherwise be missed.

Through our previous work at the CSA Centre, it had become clear that identifying and articulating patterns of offending and the contexts in which CSA occurs was key to developing a better understanding of and response to CSA. We wanted to explore the nature of the abuse being committed. For example, what connections exist between victims and perpetrators? What does the abuse consist of? Where and how does it take place? Without clear definitions of different types of CSA and a shared understanding of the ways in which CSA takes place, a clear direction for future knowledge development in this area is unattainable.

The current study, then, arose from our concern to look at the whole of CSA anew and to focus on offending - the acts and patterns of behaviour involved, and their contexts rather than on perpetrators as individuals. We believe that a better understanding of offending itself will help to provide greater clarity and consistency in the ways in which agencies identify and respond to CSA, and will support policymakers and practitioners to tackle CSA offending in a more informed manner.
Initial research to develop the typology was carried out by CATS. It involved analysis of 157 case files provided by Norfolk Constabulary, the Metropolitan Police Service, Sussex

Police, West Yorkshire Police and the Lucy Faithfull Foundation, plus 10 focus groups with professionals from a range of statutory and voluntary sector organisations across England and Wales.

Further review, testing and refining of the typology was carried out by the CSA Centre. This involved review by the National Crime Agency (NCA), practitioners at conferences hosted by the National Organisation for the Treatment of Abusers (NOTA) and Rape Crisis England \& Wales (RCEW), and the wider team at the CSA Centre.

The typology sets outs nine types of child sexual abuse. It should be noted that there is no implied sense of hierarchy in the presentation of the types; and that, although there are overlaps between different types, each type seeks to describe a specific context that comprises a set of behaviours and features that define a particular type of abuse.

It should also be noted that the focus of this typology is on offending by adults. The contexts of abuse by under-18s are likely to differ significantly from those of abuse committed by adults, and should be approached separately and in a different way.
Without shared understanding
of the ways in which CSA
takes place, a clear direction
for knowledge development
in this area is unattainable 

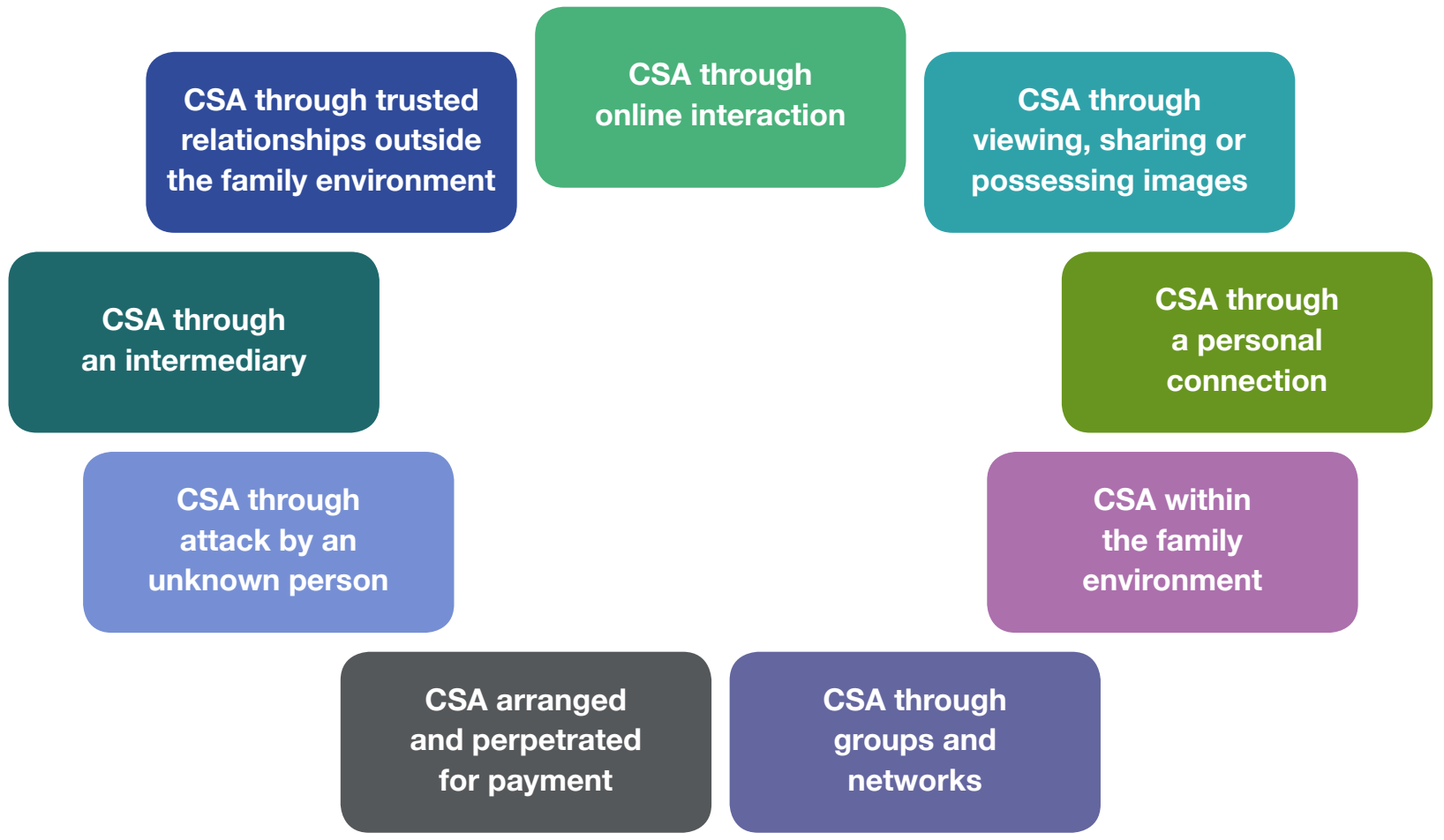

Child sexual abuse within the family

environment. This type focuses on the sexual abuse of a child or young person by an adult family member, or by an adult who is connected to the family or to one of its members.

\section{Child sexual abuse through trusted relationships} outside the family environment. This type focuses on the sexual abuse of a child or young person by someone who holds a position of authority over them as a result of a professional or vocational role. It includes CSA carried out in institutions but also in the community, both in the UK and overseas, where the perpetrator is able to establish a position of power (in relation to the child or young person, their family and/or the local community) through the trust implied by their role.

Child sexual abuse through an intermediary. This type focuses on sexual abuse of a child or young person which is carried out by more than one perpetrator; the perpetrator who initiates the abuse (the initiating perpetrator) seeks to gain access to the child, or to images of the child, through another perpetrator (the intermediary perpetrator). The intermediary perpetrator may believe they are in an intimate relationship with the initiating perpetrator, or they may be coerced into facilitating and/or committing the abuse.

Child sexual abuse through online interaction. This type of abuse focuses specifically on situations where a perpetrator, operating online, encourages/deceives/ coerces a child or young person to take part in online sexualised conversations or sexual acts, and/or to produce images (photos or videos) of themselves that they share with the perpetrator online.
Child sexual abuse through viewing, sharing or possessing images. This type of abuse focuses on the viewing of images of CSA that have already been created. This can include viewing, possessing and sharing images (photos or videos) with others, generally (but not exclusively) online.

Child sexual abuse through groups and networks. This type centres on sexual abuse committed by perpetrators who are part of a group or network. This may be a social group, gang or network that meets in person, or a group or network in which members interact online and remain anonymous. The abuse may include contact abuse and/or the creation/sharing of images of CSA. It is facilitated and encouraged through the perpetrators' membership of the group/network, i.e. the members may jointly plan and/or incite each other to commit abuse or escalate the abuse.

Child sexual abuse arranged and perpetrated for payment. This type involves the sexual abuse of a child or young person by one or more perpetrators where, in return for payment (either financial or other), a perpetrator ('the seller') offers other perpetrators ('buyers') access to the child or young person for contact abuse and/or creates and sells images (photos or videos) of abuse, e.g. via live-streaming.

Child sexual abuse through a personal connection. This type of abuse describes abuse committed by a perpetrator who establishes a personal connection with a child or young person and grooms or coerces them into sexual abuse.

Child sexual abuse through attack by an unknown person. This type of abuse describes situations where a perpetrator, who is unknown to the child or young person, attacks and sexually assaults them. 
While the development of the typology to date has involved a process of creating, refining and testing it against different datasets, and has incorporated a wide range of perspectives, it is important to highlight the complexities of work in this field and to acknowledge the limitations of this typology. With regard to the case files used in the typology's development:

- The sample of case files cannot be taken to be representative of all cases of CSA, particularly as only a minority of cases of CSA are actually reported.

- The data in the case files was recorded for the purpose of investigation, support and case management, and not for the purpose of developing an understanding of the context of the offending.

And with regard to the nature of CSA itself:

- Online interaction is now so ubiquitous that it is likely to feature in almost all cases of CSA. At the same time, it is clear that the online world has created new environments providing perpetrators with opportunities and channels to facilitate CSA.

- CSA is complex, and it is important to understand that individual cases will not always fit neatly into any one specific type as defined in the typology. Recognising and articulating this complexity is imperative, both for the identification and disruption of CSA and for effective response to the children and young people who experience it.
We hope that this typology will make a significant contribution to both policy and practice, by illuminating and more fully articulating the range of contexts in which CSA offending takes place and increasing understanding of the nature and dynamics of different forms of abuse. It is intended to inform rather than direct practice, helping to improve our collective responses to CSA by developing a stronger shared understanding of the complexity of this abuse and the many different forms it can take.

CSA offending is complex, and this complexity can sometimes be daunting for both practitioners and policymakers. It is only by embracing and understanding the complexity that practice can move forward with confidence, and this typology therefore makes no attempt to simplify or present quick solutions. Rather, it aims to help practitioners, policymakers and others to see the whole picture of CSA, driving the development of responses and services that better meet the varied needs of victims and survivors by focusing on the varied contexts and dynamics in which abuse takes place. We will engage with organisations that can contribute different perspectives on and experiences of CSA, and will apply the typology to new datasets. We will be paying close attention to feedback on this typology, and we look forward to seeing how policy and practice develop in response.

\section{It is only by embracing and understanding the complexity of CSA offending that practice can move forward with confidence}




\section{Introduction}

The Centre of expertise on child sexual abuse (CSA Centre) was established in 2016 to help bring about significant and system-wide change in how child sexual abuse (CSA) is responded to locally and nationally. We do this by identifying, generating and sharing high-quality evidence of what works to prevent and tackle CSA, in order to inform both policy and practice. The CSA Centre recognises, as do many others in the field, that in order to prevent CSA from happening and protect children who are experiencing it, we must develop a better understanding of the nature of abuse as well as of those who perpetrate abuse.

\section{Aim of the work}

In 2018, the CSA Centre set out to develop a typology that would provide a new way of understanding and talking about CSA. We aimed to identify and describe a set of types of CSA offending that are not constrained by existing constructs of CSA. We sought to focus on the context of offences and draw out types that reflect different offending behaviours, rather than focusing on the characteristics of the perpetrator. The resulting typology would thus present a fuller representation of CSA offending, including both online and contact abuse, enabling us to view CSA in a new light and to make connections between different types of offending that might otherwise be missed.

The work sought to develop the typology 'from the ground up' (i.e. through the use of empirical data) so that the typology would be grounded in actual experiences of CSA, drawing upon both perpetrator and victim perspectives. Consequently, the development of the typology did not seek to align with the ways in which agencies involved in preventing, tackling and responding to CSA currently define and prioritise their work.
For example, we deliberately avoided terms such as child sexual exploitation (CSE), as research has shown that CSE is already subject to multiple definitions covering many different forms of abuse, leading to confusion and inconsistent responses in both policy and practice (see Beckett and Walker, 2017).

Recognising the complexity of CSA offending, we did not set out to create a typology that would necessarily simplify our understanding. Instead, we sought to increase understanding through articulation of a fuller range of different types of CSA. In addition, we anticipated from the outset that the typology would not be presented as a neat grid but as a series of concepts which intersect and overlap.

We decided that the focus of the typology would be on offending by adults. The contexts of abuse by under-18s are likely to differ significantly from those of abuse committed by adults, and should be approached separately and in a different way.

\section{Background}

In the first year of the CSA Centre's life, we commissioned a suite of work to better understand the scale and nature of CSA. Initially, much of this work focused on the perpetration of CSE, as we were aware that CSE was a relatively recently recognised form of CSA which required immediate focus. The studies we carried out varied in their approach, and included literature reviews, interviews with experts and case file analysis to develop new empirical evidence on the characteristics and perspectives of individuals who sexually exploit young people ${ }^{1}$. However, a finding that emerged from across the studies was the difficulty that researchers reported in understanding the boundaries between CSE and other types of CSA. 
We therefore realised that identifying and articulating patterns of offending and the contexts in which CSA occurs was key to developing a better understanding of and response to CSA. We wanted to explore the nature of the abuse being committed. For example, where does abuse take place? What connections exist between victims and perpetrators? What social contexts are at play when abuse is committed? What are the enablers of the abuse? Without clear definitions of different types of CSA and a shared understanding of the ways in which CSA takes place, a clear direction for future knowledge development in this area is unattainable.

The development of the typology presented in this report arose from our concern to look at the whole of CSA anew and to focus on offending - the acts and patterns of behaviour involved, and their contexts - rather than on perpetrators as individuals. We believe that a better understanding of offending itself will help to provide greater clarity and consistency in the ways in which agencies identify and respond to CSA, and will support policymakers and practitioners to tackle CSA offending in a more informed manner.

As a first step, the CSA Centre carried out a literature review (Pascoe and Sharples, 2020) to explore the previous development and use of typologies to better understand CSA. Key lessons from this literature review informed the methodology that we adopted in developing this typology of CSA offending. In particular, the literature review highlighted the importance of:

- shifting the focus to understand more about the abuse committed, rather than the person who committed it

- triangulating the research (i.e. using more than one approach in investigating the research question) in order to reduce uncertainty as to the reliability, validity and generalisability of the findings

- seeking different perspectives (e.g. from practitioners and victims) rather than relying solely on retrospective offender accounts of the abuse they have committed

- using data samples from different geographical locations and being transparent in the reporting of the data.

\section{Method}

The typology was developed over a number of stages. The CSA Centre commissioned the Centre for Abuse and Trauma Studies (CATS) at Middlesex University to undertake Stages 1 and 2, while Stages 3 and 4 were carried out by the CSA Centre's own research team.

Stage 1: Analysis by CATS of data held in 67 case files provided by Norfolk Constabulary, the Metropolitan Police Service and the Lucy Faithfull Foundation. This involved in-depth analysis of information in the case files, grouping cases with similar characteristics and identifying overarching terms and concepts to create an initial draft typology.

Stage 2: Testing and refining the draft typology by CATS, through the analysis of a further 90 case files from the Metropolitan Police Service, West Yorkshire Police and Sussex Police; a series of focus groups with professionals from a range of statutory and voluntary sector organisations across England and Wales; and a review by Professor Michael Seto of the work to date.

Stage 3: Further testing and refining of the typology by the CSA Centre's research team, through the analysis of a set of 572 case files from Saint Mary's Sexual Assault Referral Centre in Manchester.

Stage 4: Final review and editing, led by the CSA Centre's research team, culminating in the production of the new typology. This involved feedback from the National Crime Agency, practitioners at conferences hosted by the National Organisation for the Treatment of Abusers and Rape Crisis England \& Wales, and other staff at the CSA Centre.

Appendix 1 provides a detailed description of the methodology employed to develop the typology through each of these stages. 


\section{Limitations}

It is important to acknowledge the limitations of this typology, which highlight the challenges of work in this field:

- CSA offending is complex and much of it is hidden. Among adults who told the Crime Survey for England and Wales 2019 that they had experienced contact CSA before the age of 16 , for example, fewer than one in three said they had told anyone about it at the time - and the number who had reported their abuse to the police, a teacher or a healthcare professional was far lower (Office for National Statistics, 2020).

- The sample of case files on which the typology was based cannot be seen as representative of all cases of known CSA. This is because the underpinning research employed a qualitative approach, which brought both variety and diversity to the research but did not allow for large numbers of files to be reviewed. Furthermore, the sample was purposively selected and drawn from a relatively small number of agencies, on the basis that their different perspectives could shed light on different contexts of CSA offending; there is no comprehensive national database of CSA cases.

- The data in the case files had been recorded for the purpose of investigation, support and case management, and not for the purpose of developing an understanding of the context of offending. As a result, some data was missing or unclear in the case files.

- The focus groups and discussions with other professionals did not cover all professionals working in the field, so there will be other perspectives to consider when refining the typology further in the future.

\section{Definitions}

The new typology presented in this report is based on a set of terms which are often used and understood in different ways. The following definitions are used in the typology.

\section{What is a typology?}

Typologies are a way of classifying items (e.g. individuals, situations, environments) by grouping them according to their similarities and differences so that they can be studied and understood in more detail. Typologies therefore enable us to make sense of complex data by providing categories for sorting and comparing data.

\section{What do we mean by CSA?}

Our definition of CSA uses the definition set out by the UK Government in its statutory guidance, Working Together to Safeguard Children:

"[CSA] involves forcing or enticing a child or young person to take part in sexual activities, not necessarily involving a high level of violence, whether or not the child is aware of what is happening. The activities may involve physical contact, including assault by penetration (for example, rape or oral sex) or nonpenetrative acts such as masturbation, kissing, rubbing and touching outside of clothing. They may also include noncontact activities, such as involving children in looking at, or in the production of, sexual images, watching sexual activities, encouraging children to behave in sexually inappropriate ways, or grooming a child in preparation for abuse. Sexual abuse can take place online, and technology can be used to facilitate offline abuse. Sexual abuse is not solely perpetrated by adult males. Women can also commit acts of sexual abuse, as can other children." (Department for Education, 2018). 


\section{Who does the term 'victim' refer to?}

Where appropriate, the CSA Centre uses the term 'victim and survivor' to describe children and young people who have experienced CSA. In the current study, however, we know very little of the situation of the children and young people beyond the fact of their abuse, so in the typology we use the term 'victim'.

\section{Who does the term 'perpetrator' refer to?}

The term 'perpetrator' is used here to refer to an adult (aged over 18) who has been involved in committing CSA. It encompasses both those who have been accused or convicted of CSA and those who have self-identified as having committed CSA. The term is used for convenience, as the typology's focus is on offending rather than individuals; however, we are aware of ongoing debate about the terminology used to describe those who perpetrate sexual abuse against children, and the impact of labels on individuals' sense of self and capacity to change their behaviours.

\section{What do we mean by context?}

The typology of CSA offending seeks to define different types of abuse by focusing on the context in which abuse is committed. This means that we have tried to describe contextual factors around different types of offending by considering four key factors, as shown in Figure 1.

These contextual factors emerged through the case file study conducted by CATS (see Appendix 1, sections on Stage 1 and Stage 2) and were based on themes that could be identified across the case files, such as the relationship between the perpetrator(s) and the victim ('connection') and the location where offences occurred. These contextual factors were then used by the CATS and CSA Centre research teams to identify what it was that distinguished groupings of files distinct from one another. Although a greater number of factors had been used in the early stages of the typology development, both research teams focused on these factors as they emerged consistently across the case files.

Figure 1. Contextual factors in child sexual abuse

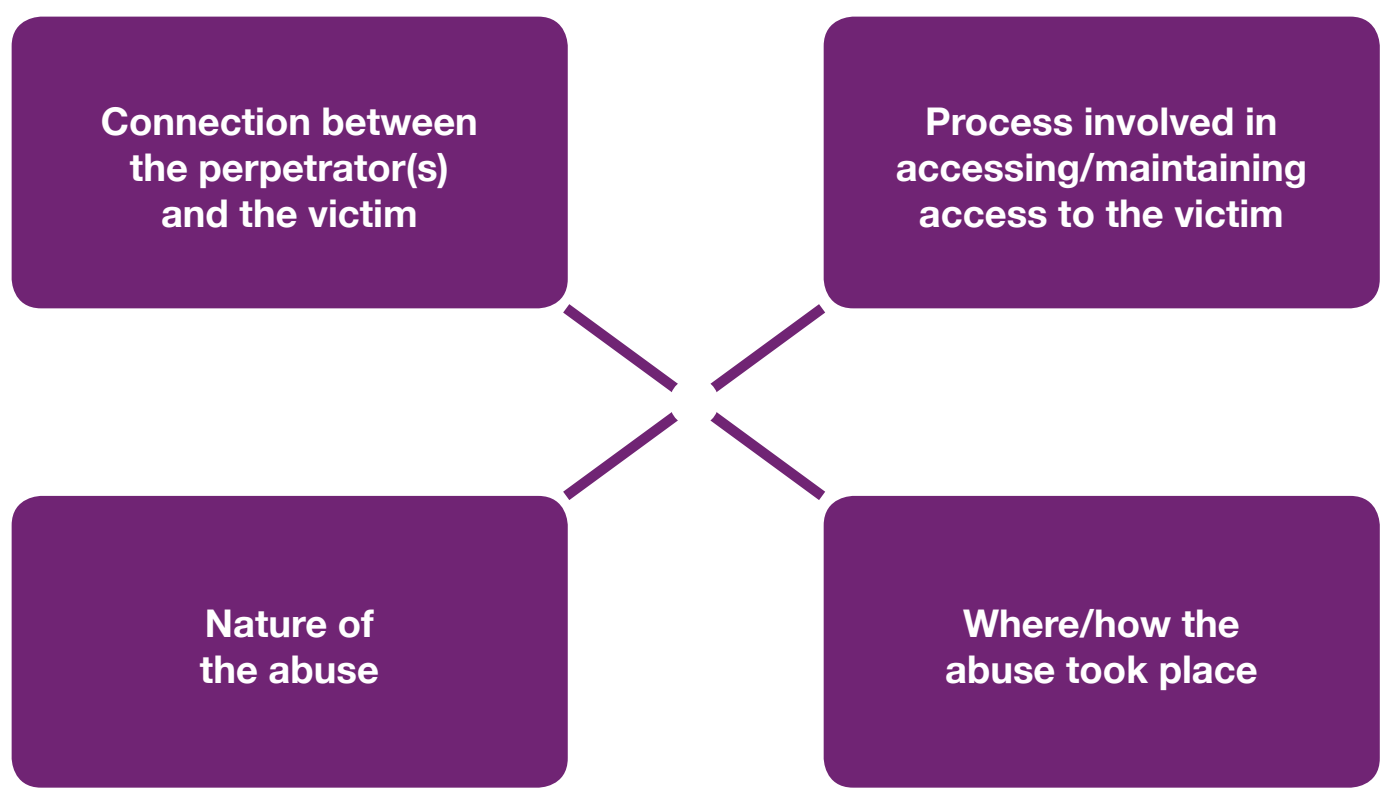




\section{The typology}

Figure 2 presents an overview of the new typology of CSA offending that has been developed and refined through the various stages of the research study. Please note:

- There is no attempt to place the types of offending in any kind of hierarchy; the arrangement of Figure 2 and the order in which this chapter presents the types should not be taken to imply any attempt to prioritise different types over others, or to show connections between types.

- Each different type reflects a distinct combination of characteristics. However, CSA is complex and there are overlaps between the types. Individual cases may therefore not fit neatly into one type; perpetrators may commit, and victims may experience, multiple types of abuse.
- Online interactions can be seen across all the different types, but some types focus specifically on online perpetration of CSA.

- This typology relates solely to CSA perpetrated by adults (aged over 18).

In this chapter, case examples have been selected to illustrate each particular type of CSA offending; in some cases, however, the offending described in the case example may not fit solely within that type, because there may be features of multiple types of CSA within an individual case. Unless otherwise indicated, all types and case examples are drawn from the analysis of police files and the Lucy Faithfull Foundation's case files, conducted by the Centre for Abuse and Trauma Studies.

Figure 2: The typology

CSA through trusted relationships outside the family environment
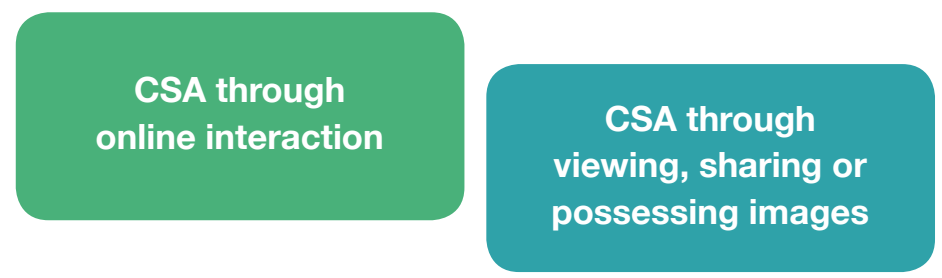

\section{CSA through \\ a personal \\ connection}

\section{an intermediary}

CSA through

attack by an

unknown person
CSA within

the family

environment
CSA arranged and perpetrated for payment

\section{CSA through groups and networks}




\section{Child sexual abuse within the family environment}

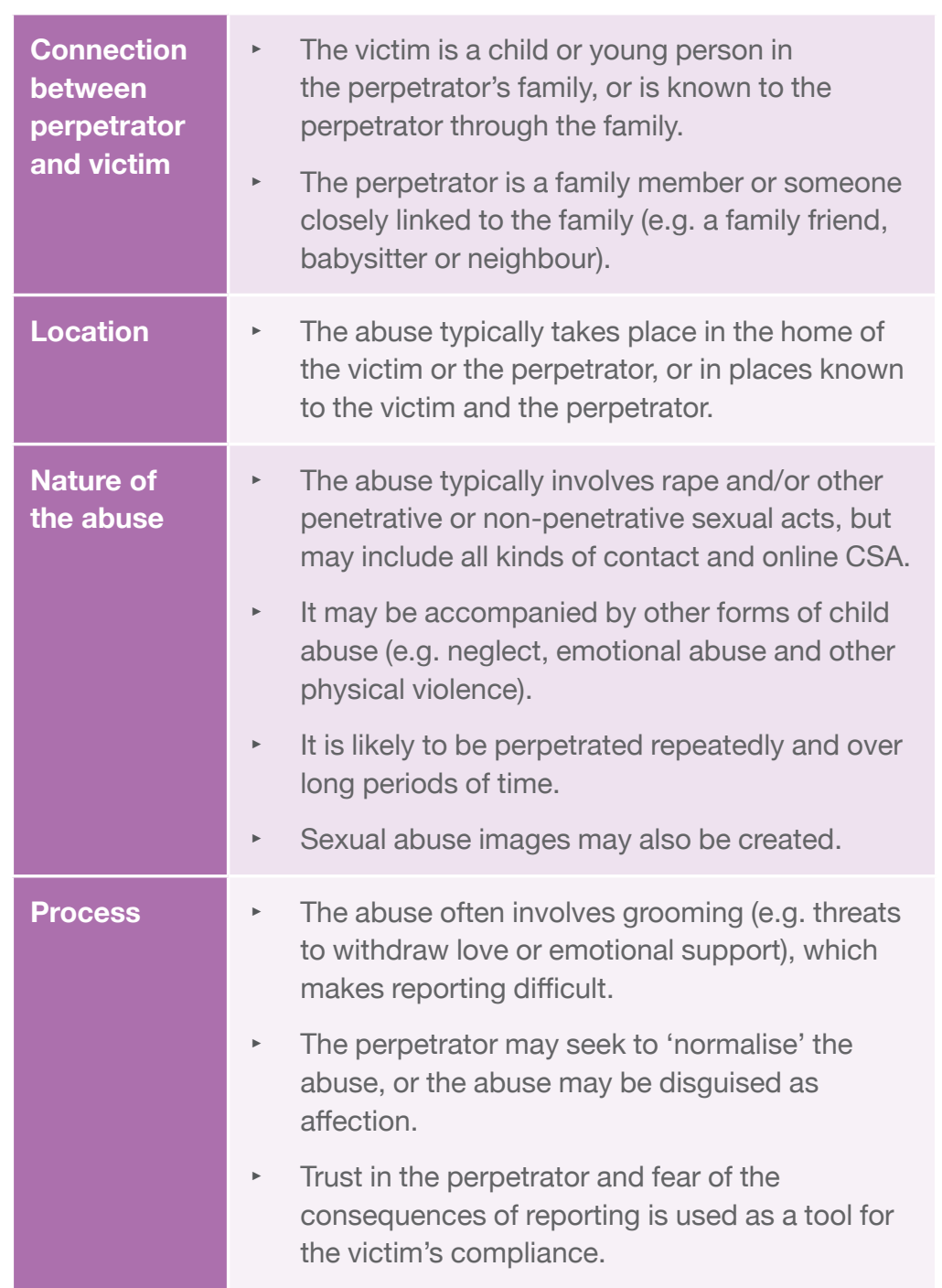

This type focuses on the sexual abuse of a child or young person by an adult family member, or by an adult who is connected to the family or to one of its members.

\section{Case example A}

This case involved a grandfather abusing his grandson. The abuse began when the boy was eight and continued for approximately four years, taking place when the boy stayed at his grandfather's home overnight or during the holidays. The grandfather sexually abused the boy by showing him videos and coercing him to engage in oral sex. The abuse occurred repeatedly at the grandfather's home, or in the car when other individuals were in the home.

\section{Case example B}

This case involved a stepfather in his mid-forties who abused his 17-year-old stepdaughter. He lived with the victim, her mother and a younger sibling. The abuse occurred after the girl had been at a family party and the stepfather followed her into her bedroom. He then got into bed with her and raped her. The following morning, he returned to her bed and repeated the rape. A day later, the girl told her mother of the abuse and the mother reported the stepfather to the police.

\section{Case example C}

This was a case where a 40-year-old man abused children in two different families. The man lived in the neighbourhood and was considered a family friend by many of the households in the area. In one case, he gave a 12-year-old girl a mobile phone so that they could communicate without her parents' knowledge. He would then invite her to his home and take her on picnics, where the abuse took place. Alcohol was given to the girl, and the man took images of the abuse and subsequently distributed them to others. The abuse included rape and sexual assault, and continued over a period of two years. Concerns were raised by the school safeguarding team when another girl was seen holding hands and kissing the man, and the police became involved. 


\section{Child sexual abuse through trusted relationships outside the family environment}
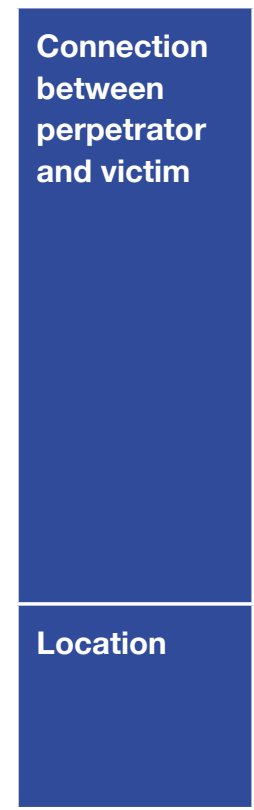

Nature of

the abuse

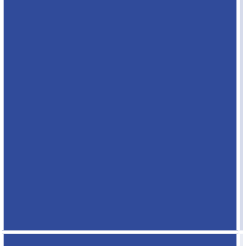

Process
- The victim is a child or young person who knows the perpetrator through the perpetrator's professional/vocational role (e.g. education, care home, sports club, faith or charitable organisation).

- The perpetrator is likely to be in a position of authority over the victim (e.g. a teacher, coach, care worker).

- The authority over the victim may also be inferred because of their role (e.g. school caretaker, aid worker).

- The perpetrator is perceived to be someone who can be trusted because of the role they hold.

- The abuse may happen in places connected with the institution/organisation, but may also take place in the perpetrator's home, in the victim's home or on trips away.

- The abuse typically involves rape and/or other penetrative or non-penetrative sexual acts.

- It may involve frequent contact (e.g. at a weekly sporting or religious event) and may be perpetrated over long periods of time.

- Sexual abuse images may also be created.

- Access to the victim may be facilitated by the esteem in which the perpetrator is held by the local community.

- The perpetrator may take advantage of a weaker safeguarding response overseas or in less regulated roles/sectors in order to gain access to victims.

- The abuse may involve a grooming process, beginning as an appropriate relationship before escalating into an abusive one.

- The abuse may be disguised as affection, and the victim may believe they are in an intimate relationship with the perpetrator.

- It may involve promises of gifts or privileges to the victim, in exchange for their continued engagement in or silence about the abuse.

- Technology may be used to maintain the offending, e.g. using images taken of the victim to pressurise them into allowing further abuse.
This type focuses on the sexual abuse of a child or young person by someone who holds a position of authority over them as a result of a professional or vocational role. It includes CSA carried out in institutions but also in the community, both in the UK and overseas, where the perpetrator is able to establish a position of power (in relation to the child or young person, their family and/ or the local community) through the trust implied by their role.

\section{Case example D}

This case concerned a 37-year-old male social worker who made contact with his victims through his professional role. He would invite children to football matches or music gigs and pay for their tickets. He would also invite children to his house to play games and listen to music, encouraging them to visit at any time of the day, and would allow them to spend the night at his house. One of the children (aged 15 when the offending began) would visit the social worker's home at the weekend and play games with him and other young people there. On one occasion, the social worker initiated a game of hide and seek, during which he hid with the boy and sexually abused him. On another occasion, the boy was sexually abused when he was sleeping at the social worker's home. The boy reported the abuse to the police several years later.

\section{Case example E}

This case concerned a 27-year-old female teacher who abused a 16-year-old boy. The teacher started giving the boy extra revision support to help him prepare for his upcoming GCSE exams. She then communicated with the boy on social media, where she sent naked pictures and short videos of herself and persuaded him to reciprocate with naked photographs of himself. When the teacher asked him to have sex with her, the boy reported the abuse. 


\section{Child sexual abuse through an intermediary}

\begin{tabular}{|c|c|c|}
\hline $\begin{array}{l}\text { Connection } \\
\text { between } \\
\text { perpetrators } \\
\text { and victim }\end{array}$ & $\begin{array}{l}\text { The victim is a child or young person accessible } \\
\text { to the initiating perpetrator through an } \\
\text { intermediary perpetrator. } \\
\text { The initiating perpetrator holds power over } \\
\text { the intermediary perpetrator and uses them to } \\
\text { produce and share sexually abusive images of } \\
\text { the victim and/or to provide access to the victim. } \\
\text { The intermediary perpetrator is in a position } \\
\text { that gives them power over the victim and/or } \\
\text { engenders trust with the victim or the victim's } \\
\text { family (e.g. a parent or childcare worker). }\end{array}$ & $\begin{array}{l}\text { This type focuses on sexual abuse of a child } \\
\text { or young person which is carried out by } \\
\text { more than one perpetrator; the perpetrator } \\
\text { who initiates the abuse (the initiating } \\
\text { perpetrator) seeks to gain access to the child, } \\
\text { or to images of the child, through another } \\
\text { perpetrator (the intermediary perpetrator). } \\
\text { The intermediary perpetrator may believe } \\
\text { they are in an intimate relationship with the } \\
\text { initiating perpetrator, or they may be coerced } \\
\text { into facilitating and/or committing the abuse. }\end{array}$ \\
\hline
\end{tabular}

Location

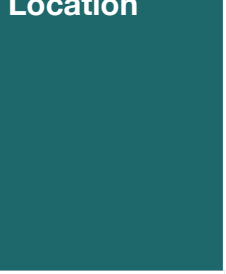

Nature of

the abuse
- The intermediary perpetrator has direct contact with the victim, and the abuse is therefore likely to occur in their home, their workplace or the victim's home.

- The initiating perpetrator may be located anywhere, including in a different country.

- The abuse may involve the intermediary perpetrator abusing the victim and/or taking images of sexual abuse happening to the victim, on behalf of the initiating perpetrator. This can include real-time live-streaming.

- It may also involve the intermediary perpetrator facilitating access for the initiating perpetrator to have direct contact with the victim to commit sexual abuse.

\section{Process}

- The initiating perpetrator seeks out an intermediary who can provide access to children through their family, work or social connections.

- The initiating perpetrator exploits the intermediary perpetrator's financial or emotional vulnerabilities in order to gain access to the victim. For example, the intermediary perpetrator may be led to believe that they are in an intimate relationship with the initiating perpetrator, or may be blackmailed or threatened in order to carry out/facilitate the abuse.

\section{Case example $\mathrm{F}$}

This case involved a man (the initiating perpetrator) who created multiple fake identities in online parenting chatrooms. $\mathrm{He}$ made contact with a single mother in her late twenties (the intermediary perpetrator) who was unemployed and finding it difficult to afford her rent payments. The man gave the single mother money to take sexual photographs and videos of her five-year-old son, which she sent to him over the internet. This abuse took place over a period of 12 to 18 months and was discovered when the man was arrested for another offence and had his computer equipment seized and forensically examined: a large collection of images of CSA, which he had been disseminating to others, was found.

\section{Case example G}

In this case, a male initiating perpetrator used an online chat room to befriend a vulnerable man in his early thirties (the intermediary perpetrator) who volunteered at a local afterschool club for children aged five to seven. The volunteer had mental health issues and was socially isolated. An online friendship developed over WhatsApp, where the initiating perpetrator instigated sexual conversations which led to the two men exchanging adult legal pornography and discussing the content. As the conversations progressed, the initiating perpetrator started asking the intermediary perpetrator about the children at the afterschool club and asked to see photographs of them. The intermediary perpetrator was persuaded to find opportunities to take children to the toilet, take photos and videos of them touching their genitals, and send the images to the initiating perpetrator. The abuse was identified when another volunteer reported concerning behaviour to the police. 


\section{Child sexual abuse through online interaction}

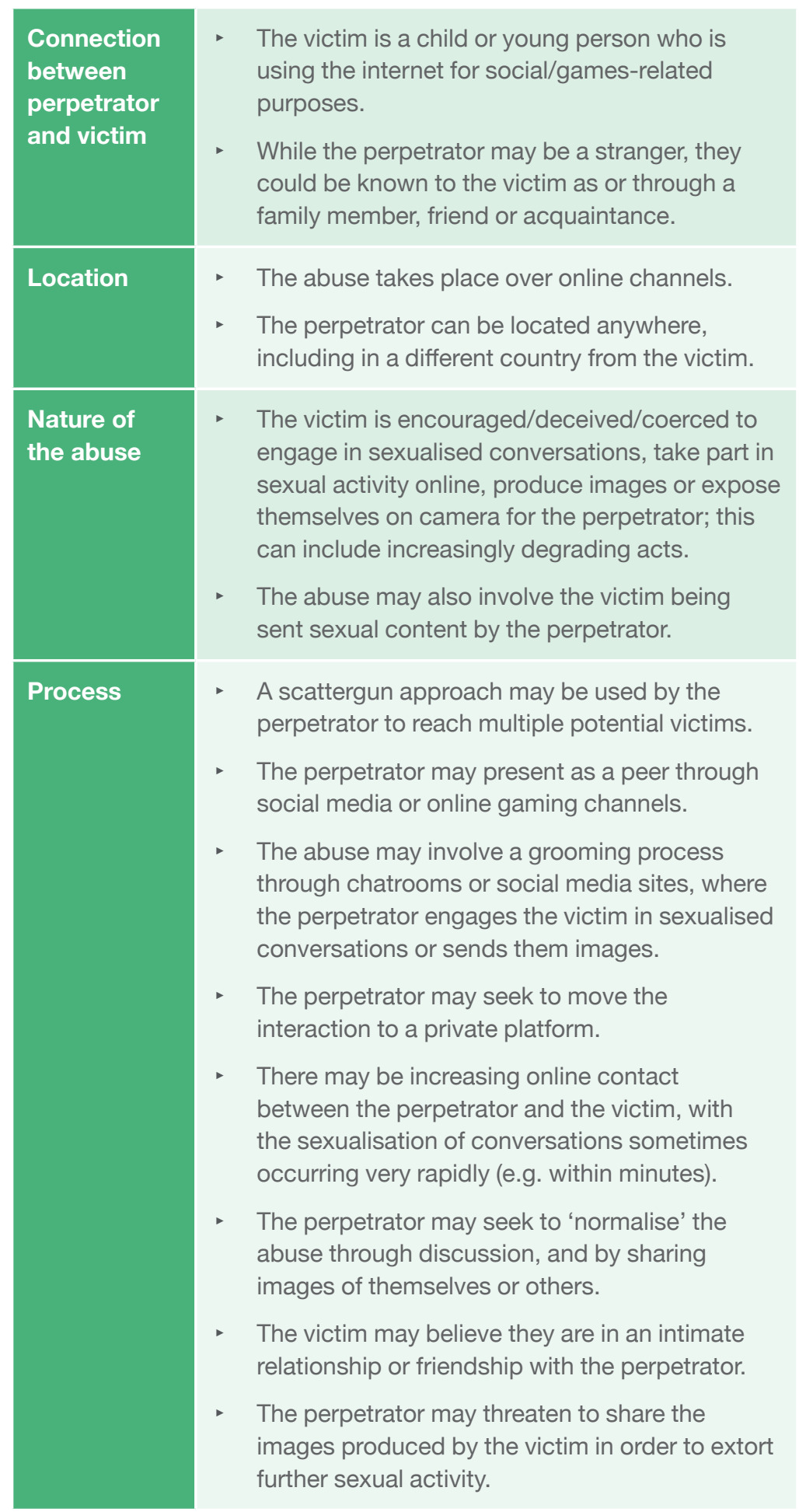

This type of abuse focuses specifically on situations where a perpetrator, operating online, encourages/deceives/coerces a child or young person to take part in online sexualised conversations or sexual acts, and/or to produce images (photos or videos) of themselves which they share with the perpetrator online. This type does not involve contact abuse; where online sexual abuse leads to other types of abuse, this becomes an additional type of abuse.

\section{Case example $\mathrm{H}$}

This case involved a 21-year-old man who made a series of targeted approaches to girls through social media, commencing conversations in an innocuous manner with a view to persuading the girls to send him photographs of themselves. In one case, the man made contact with a 15-year-old girl on a fan site for a popular band. He started sending her private messages containing sexual lyrics from the band's songs, and persuaded her to send him pictures of her breasts. The exchanges continued, with the man sending pictures of his penis. Eventually the girl's older sister discovered the communication and reported it to her parents and the police.

\section{Case example $J$}

In this case, a man befriended an eightyear-old-boy through online gaming. The communication began with the man saying that he wanted to have oral sex with the boy. The man then said he wanted to move the conversation onto a more private platform, and taught the boy how to download WhatsApp. The boy was asked to film himself in his underwear and to send the man photos of himself in his underwear. The boy sent the man six images of himself so that 'he could please him'. The police were informed when the boy's father found the online conversation on the PlayStation. 


\section{Child sexual abuse through viewing, sharing or possessing images}

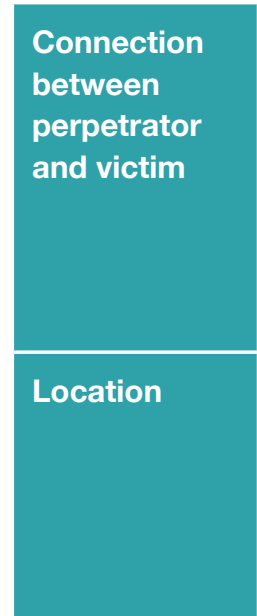

\section{Nature of}

the abuse
- The victim is a child or young person who has been abused, and images of their abuse have been taken; these images are subsequently shared.

- The perpetrator does not typically have any direct connection with the victim but is abusing them by viewing images provided by others.

- Obtaining and sharing images occurs primarily on the open net, including through private messaging between perpetrators.

- The victim and the perpetrator can be located anywhere, including in different countries.

- The abuse involves viewing and sharing images of CSA, including photos, videos and recorded live-streaming.

- Images can depict a wide range of sexual abuse, as well as other physical violence and degrading acts.

- Once made available, the images can be in wide circulation and very difficult to remove.

Process
- Individual perpetrators may find CSA content by searching online, or may acquire content from others.

- The process may involve accessing images through difficult-to-access sites (e.g. dark web).

- It may also involve viewing of images in hard copy as well as digital content.
This type of abuse focuses on the viewing of images of CSA that have already been created. This can include viewing, possessing and sharing images (photos or videos) with others, generally (but not exclusively) online.

\section{Case example $\mathrm{K}$}

This case involved a single man in his midtwenties who downloaded and shared images of CSA. The man was caught viewing material on his work computer by a colleague, who reported him to the police. He was found to be in possession of more than 5,000 images of CSA. Analysis of his computer and mobile phones revealed links to a wide network of other perpetrators with whom he was sharing the images. 


\section{Child sexual abuse through groups and networks}
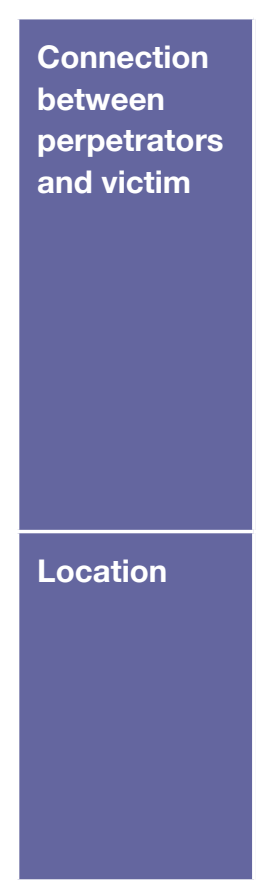

Nature of

the abuse
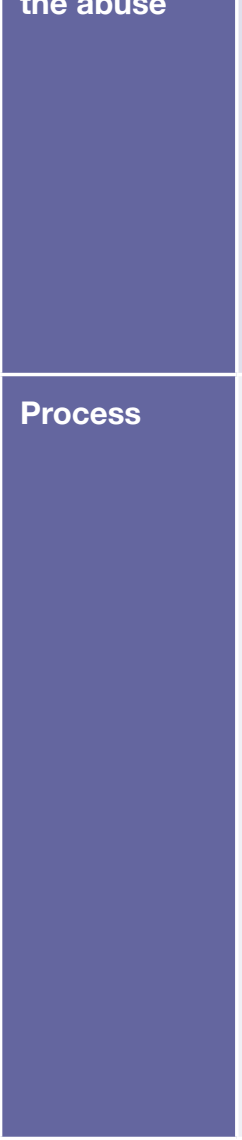

- The victim is a child or young person who is accessible to some or all of the perpetrators through social connections or online.

- Multiple perpetrators (two or more) are involved, who are part of a group, gang or network.

- Some groups exist solely for the purpose of perpetrating CSA while others do not have this as their express purpose.

- Groups may interact online, in spaces where the members may be connected anonymously.

- The abuse may happen in many different places, including the perpetrators' homes, local public places, or private spaces that the perpetrators have access to.

- In online groups/networks, images of the abuse are concurrently or subsequently shared online between members.

- The abuse can involve any kinds of CSA, including rape and/or other penetrative or non-penetrative sexual acts, online and livestreaming, and other physical violence.

- It typically involves the victim being abused by multiple perpetrators.

- It may also involve generating, viewing and sharing images of CSA, including photos, videos and recorded live-streaming.

- The perpetrators may commit the abuse as a form of initiation into the group, to advance their status in the group or to punish others. They may incite one another to commit abuse or escalate the abuse.

- In some online networks, the perpetrators may be encouraged by others to create new images of abuse as a condition of access to forums or further CSA images.

- In some cases, access to the victim is gained through a grooming process involving gifts, alcohol or drugs, which may also be used to control the victim.

- Violence and threats of harm to the victim's family and friends may be used to commit/ maintain the abuse.
This type centres on sexual abuse committed by perpetrators who are part of a group or network. This may be a social group, gang or network that meets in person, or a group or network in which members interact online and remain anonymous. The abuse may include contact abuse and/or the creation/sharing of images (photos or videos) of CSA. It is facilitated and encouraged through the perpetrators' membership of the group/ network, i.e. the members may jointly plan and/or incite one another to commit abuse or escalate the abuse.

\section{Case example L}

This case involved a group of five men who sexually abused two adolescent girls and made them available for others to abuse. Initial contact with the girls was made through an online discussion forum based on a shared interest in a particular music scene. The men arranged to meet the girls at an event, and persuaded the girls to accompany them to a house party. Both girls were given alcohol and 'legal high' drugs. They were then subjected to sexual abuse, including rape, by multiple men, who took images of them and shared these on social media. Others were sent text messages inviting them to join the abuse. The images were also made available through online forums, where they were paid for, and subsequently became available in CSA image collections on the dark web.

\section{Case example $\mathrm{M}^{2}$}

This case concerned two men who created and maintained an online chat channel dedicated to distributing images of CSA. The two men had developed a close online relationship in which one man described the other as his 'second in command'. This second man created a fake identity and used this to make contact with victims through a popular website. He told them that they could earn money by sending him explicit pictures or live streaming videos of themselves; they were subsequently told that their images would be made public if they did not supply further images. 


\section{Case example $\mathrm{N}^{3}$}

This case concerned eight men who used social media to share images and live-stream videos of children being sexually abused. Most of the group's planning and communication took place online, but they would arrange to meet in person - often travelling long distances - when they gained access to a victim. If only one member could access the victim, the abuse would be live-streamed to the others. The group was discovered after one member of the group was arrested and admitted that he had sexually abused a child under the age of five. 


\section{Child sexual abuse arranged and perpetrated for payment}
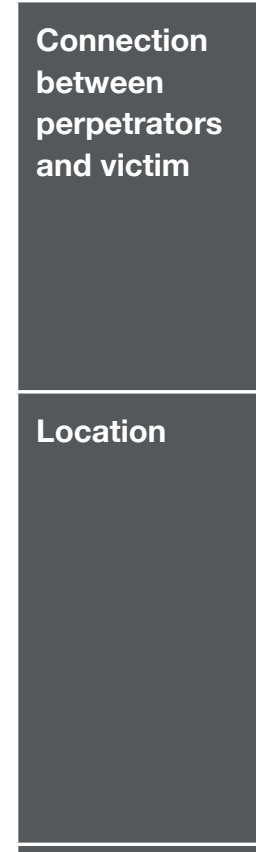

Nature of

the abuse
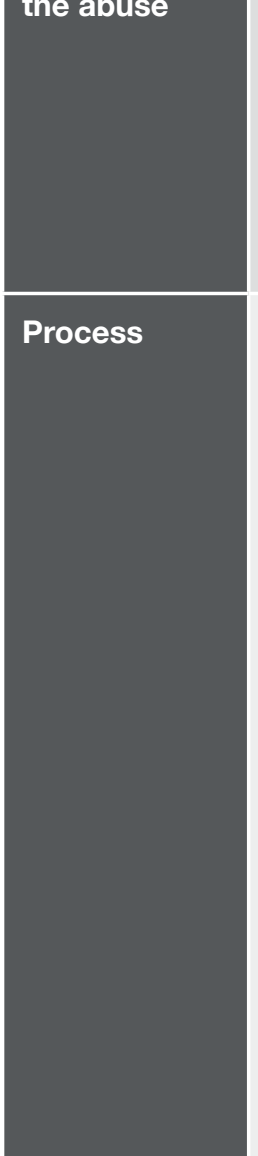

Access to the victim is gained and maintained by one perpetrator ('the seller') by various means, such as through their connection to the victim as a family member, socially, or through trafficking/modern slavery.

- The seller is linked with other perpetrators ('buyers') who are paying to abuse the victim through contact or online (or both).

- The abuse may happen in many different places, including the perpetrators' homes/ premises or private spaces that they have access to.

- The buyers may travel to other countries where they pay to abuse children or young people.

- They may also pay to facilitate/orchestrate abuse that is occurring elsewhere but is shared online.

- The abuse may involve all kinds of sexual abuse, and may also include other physical violence.

- It typically involves the victim being abused by multiple perpetrators.

- The abuse can include image creation and both recorded and real-time live-streaming of abuse.

- The seller gains financially from the abuse.

- Control of the victim may be established by the seller through their connection as a family member, or by making the victim believe they are in an intimate relationship.

- Alternatively, the seller may gain and maintain control over the victim through human trafficking/modern slavery.

- Force may be used to commit the abuse and sustain the abusive situation, including threats of harm to the victim's family and friends.

- The victim may be held against their will for prolonged periods of time.

- The victim may be groomed to accept the abuse.

- The threat of sharing or publishing images of the abuse may be used to extort further compliance.
This type involves the sexual abuse of a child or young person by one or more perpetrators where, in return for payment (either financial or other), a perpetrator ('the seller') offers other perpetrators ('buyers') access to the child or young person for contact abuse and/or creates and sells images (photos or videos) of abuse, e.g. via live-streaming.

\section{Case example P}

This case involved two parents who made their daughters, aged 12 and 14, available to be sexually abused for financial return on a regular basis over a three-year period. The abuse was arranged online through a network of abusers. Arrangements were made and paid for by this network for the family to visit a hotel in the Mediterranean. The trips were presented as family holidays, but the parents would arrange for the girls to be abused by different men while they were there. The abuse was also filmed. The parents told the girls that they would not be able to have clothes, food or holidays if they did not do as the abusers wished. The abuse was identified and reported to police by the hotel manager, who was concerned about 'unusual' activities.

\section{Case example $Q^{4}$}

This case involved a male perpetrator who sent thousands of pounds over several years to known facilitators of live-streamed child sex abuse in the Philippines. He also contacted the facilitators with the aim of travelling to the Philippines to abuse girls himself, although there is no evidence that the trip occurred. When he was arrested, images of CSA were found on his phone, and he admitted paying others to commit CSA as well as seeking to sexually abuse a child and make images of CSA. 


\section{Child sexual abuse through a personal connection ${ }^{5}$}

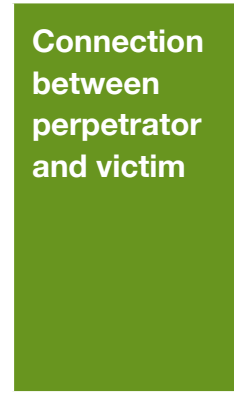

Location

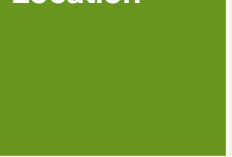

Nature of

the abuse

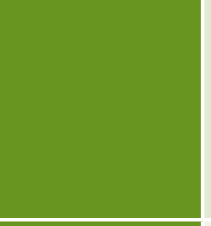

Process

- The abuse is likely to involve a grooming process which often begins online through befriending, sometimes in the guise of romantic interest.

- The perpetrator may have initially connected with the victim through social media or online gaming channels but then arranges to meet them in person. This can happen very quickly, with as few as one or two contacts before the abuse starts.

- The perpetrator may approach multiple potential victims.

- The victim may believe they are in an intimate relationship with the perpetrator.

- The threat of sharing or publishing images of the abuse may be used to extort further sexual activity.
This type describes abuse committed by a perpetrator who establishes a personal connection with a child or young person and grooms or coerces them into sexual abuse.

\section{Case example $\mathrm{R}$}

This case involved a 13-year-old girl who was approached on the street by a man in his thirties and asked if she would like to do some modelling. She went with the man to his flat, where they chatted and he gave her alcohol. He then took photographs, including topless ones, for which he paid her. The girl went back on two other occasions for more photographs, and on each occasion he paid her. On the last occasion, she was forced to perform oral sex on him in the presence of two other men, and was asked if she would have sex with one of these men.

5 This type was identified through the analysis of the Saint Mary's Sexual Assault Referral Centre (SARC) dataset by the CSA Centre. 


\section{Child sexual abuse through attack by an unknown person ${ }^{6}$}

\begin{tabular}{l|l}
\hline $\begin{array}{l}\text { Connection } \\
\text { between } \\
\text { perpetrator } \\
\text { and victim }\end{array}$ & $\begin{array}{l}\text { The victim is a child or young person who has } \\
\text { no previous connection with the perpetrator. }\end{array}$ \\
\hline Location & $\begin{array}{l}\text { The abuse typically happens in a public space } \\
\text { (e.g. a park or a street) or at an event (e.g. a } \\
\text { house party), but the victim may be moved to } \\
\text { a more secluded location or attacked in their } \\
\text { own home. }\end{array}$ \\
\hline $\begin{array}{l}\text { Nature of } \\
\text { the abuse }\end{array}$ & $\begin{array}{l}\text { The abuse typically involves rape and/or other } \\
\text { penetrative or non-penetrative sexual acts. } \\
\text { It often involves other physical violence. } \\
\text { It may also involve the perpetrator exposing } \\
\text { their genitals to the victim. } \\
\text { Sexual abuse images may also be created. }\end{array}$ \\
\hline Process & The abuse involves a sudden attack with \\
physical force and/or threats.
\end{tabular}

This type of abuse describes situations in which a perpetrator, who is unknown to the child or young person, attacks and sexually assaults them.

\section{Case example $\mathrm{S}^{7}$}

A 13-year-old girl was assaulted and raped by a man while she was playing hide and seek with friends in the park near her home.

\section{Case example $T^{7}$}

A 16-year-old girl had been out with friends. She had left them and was walking home when a man in a car offered her a lift home. She accepted the lift and got into his car. He then drove her to a quiet spot and began sexually assaulting her before she managed to get out of the car and run away.

\section{Case example $\mathrm{U}^{7}$}

A 16-year-old girl was walking home when a man grabbed her, punched her on the head until she became unconscious, and then raped her. 


\section{Conclusion}

This new typology of child sexual abuse presents nine types of CSA offending which have emerged from this research as distinct types. In doing this, the typology seeks to provide a fuller picture of offending, which encompasses different aspects of CSA. It focuses on the context of the abuse itself, rather than on the characteristics of the person who committed the abuse, and aims to provide a framework that will inform rather than direct new thinking and practice around prevention, disruption and response to CSA.

The research underpinning this work used a range of methods to ensure its validity, including triangulation (i.e. using more than one approach to investigate the research question), an extensive file study (using diverse police force files as well as case files from voluntary sector organisations), focus groups involving professionals who work with people who have experienced or committed CSA, and a review by sector experts.

During the typology's development, four key points emerged.

Firstly, while online and offline (contact) sexual offending are often considered separately, as if the two worlds did not interrelate, this study has found that online interaction is now so ubiquitous that it is likely to feature in some form in almost all cases of CSA. It is also clear that the online world has created new environments providing perpetrators with opportunities and channels to facilitate CSA.
Secondly, by their very nature typologies aim to assist us to understand complex phenomena, and so may oversimplify. CSA is complex, yet this complexity is poorly understood. This typology presents nine different types of CSA offending which have emerged as distinct types from the data, but it is important to understand that individual 'cases' will not always fit neatly into any one of the specific types defined in the typology. It is common for perpetrators to undertake more than one type of abuse and, sadly, for victims to experience multiple forms of abuse. Recognising and articulating this complexity is imperative, both for the identification and disruption of CSA and for effective response to the children and young people who experience it.

Thirdly, as noted previously, we have purposely presented the typology in a non-hierarchical way and without any ranking. Equally, although the extent, duration and level of physical and emotional harm can vary significantly within each type, it has been important to avoid any sense of hierarchy in terms of either types or variables within types.

\section{It is important to note that individual cases of CSA will not always fit neatly into any one of the specific types defined in the typology}


Finally, while the development of the typology to date has involved a process of creating, refining and testing it against different datasets, and has incorporated a wide range of perspectives, we believe that it would be valuable to access additional datasets that reflect different perspectives on CSA. We are not yet able to provide any assessment of which types are more or less likely to co-present, or to make an assessment of the relative frequency of different types of offending, but further testing of the typology with different datasets will assist in making such assessments. For example, the CSA Centre is currently developing a further research study with voluntary organisations that hold large datasets related to CSA offending, to extend our understanding by testing the typology against a far larger number of files. In parallel with these studies, we will invite others to contribute their perspectives and experiences around CSA, particularly through engaging with organisations involved in work around transnational $\mathrm{CSA}^{8}$ and those that support and represent survivors (including organisations providing specific support to men and boys, or those working with cases of ritual abuse).

We hope that this typology will make a significant contribution to both policy and practice, by illuminating and more fully articulating the range of contexts in which CSA offending takes place, and by helping to increase understanding of the nature and dynamics of different forms of abuse. It is intended to inform rather than direct practice, helping to improve our collective responses to CSA by developing a stronger shared understanding of the complexity of this abuse and the many different forms it can take.
CSA offending is complex, and this complexity can sometimes be daunting for both practitioners and policymakers. It is only by embracing and understanding the complexity that practice can move forward with confidence, and this typology therefore makes no attempt to simplify or present quick solutions. Rather, it aims to help practitioners, policymakers and others to see the whole picture of CSA, driving the development of responses and services that better meet the varied needs of victims and survivors by focusing on the varied contexts and dynamics in which abuse takes place. We will be paying close attention to feedback on this typology, and look forward to seeing how policy and practice develop in response.
We will pay close attention to feedback on this typology, and look forward to seeing how policy and practice develop in response

8 Transnational offending involves crimes that cross borders between countries; crimes that take place in one country but whose consequences significantly affect another country; and crimes where victims transit across countries. 


\section{Appendix 1: Methodology}

This appendix describes the process involved in developing the typology in terms of its underlying approach and the methods involved in carrying out the research. The outline methodology was designed by the CSA Centre's research team and, following a competitive tender to undertake the research, the Centre for Abuse and Trauma Studies (CATS) at Middlesex University was selected to carry out Stages 1 and 2 of the work.

Developing the typology involved four stages, with Stages 1 and 2 led by CATS and Stages 3 and 4 by the CSA Centre. The underpinning research led by CATS aimed to develop the typology by employing a 'grounded theory' approach, which involved using data to build a new theory rather than seeking data to test an existing theory (see Glaser and Strauss, 1967). Grounded theory allows researchers to explore underlying processes and develop concepts, codes and categories, which are not influenced by existing conceptualisations, from the data. This meant that the typology could evolve as the research progressed, with new categories emerging or existing ones being refined.

The CSA Centre established a Development and Review Panel for the project, comprising experts from across the sector who oversaw and advised on the typology's development during the various stages of the work.

\section{Ethics}

Ethical clearance for Stages 1 and 2 of the research (led by the CATS research team), was received from both the CSA Centre's Research Ethics Committee (REC) and Middlesex University's Department of Psychology REC.

Stage 3 utilised a dataset provided by Saint Mary's Sexual Assault Referral Centre (SARC) in connection with a previous study (Karsna and Majeed-Ariss, 2019) which had been approved by the CSA Centre's REC and was carried out with the consent of Saint Mary's SARC.

All the research undertaken adhered to ethical guidelines which ensured the protection and safeguarding of participants, gatekeepers and the research teams. In addition, and in accordance with data protection procedures:

- consent had been provided by participants for their data to be used for research purposes

- all data was anonymised

- particular care was taken to ensure that any identifying details were removed from the case studies used to illustrate the typology.

\section{The research employed a 'grounded theory' approach, meaning that the typology could evolve as the research progressed}




\section{Rationale for the selection of the case files}

There is no single suitable source of data on CSA offending to draw on, since CSA is often hidden (Office for National Statistics, 2020).

Accordingly, the four stages of the typology's development utilised a range of data sources. Different organisations were approached for permission to use data from their files, on the basis that this would provide a range of perspectives which could shed light on different contexts of CSA offending:

- Police forces were approached on the basis that their case files would cover a range of offending behaviours, as well as providing the depth of information necessary to support the typology's development. The four police forces that were chosen (Norfolk Constabulary, the Metropolitan Police Service, Sussex Police and West Yorkshire Police) covered a range of geographical areas and socio-economic contexts. The research teams' existing relationships with police forces also played a role in the choice of forces to include.

- The Lucy Faithfull Foundation (LFF) works with people who have been accused or convicted of CSA, and those who are concerned about their thoughts. ${ }^{9}$ The LFF files therefore included cases where criminal justice agencies had not been involved, and it was believed that these cases would provide a different perspective from the police files.

- The Saint Mary's SARC dataset related to the cases of children and young people aged under 18, living in the Greater Manchester area, who had attended Saint Mary's SARC between April 2012 and March 2015. All cases related to substantiated, alleged or suspected CSA by an adult, and included both recent and non-recent abuse. Analysis of this dataset would provide a different perspective on CSA offending, as the cases of the children/young people seen by the SARC would not necessarily have been reported to the police or have been reflected in the LFF's files.
To ensure consistency in the data provided, criteria for the case files were agreed. The organisations participating in the research were asked to provide cases that involved:

- suspected or alleged sexual offences in England and Wales from 2017 onwards

- victims who were under the age of 18 at the time of the suspected or alleged offence

- perpetrators who were over 18 at the time of the suspected or alleged offence.

It was envisaged that using a small, purposively selected sample would provide a rich data source containing information on both perpetrators and victims, along with contextual information (such as the location and nature of the abuse) that would inform the development of the typology.

Consistency in the dataset was established by the CATS research team extracting and independently reviewing data from the case files, which were studied on the premises of the respective organisations. In addition, the research team project manager and project lead reviewed a subset of data from across the organisations to ensure that the quality of information was of a similar level.

9 The LFF works closely with frontline workers and professionals such as police officers, social workers and education staff to ensure children are as safe as they can be. It works with entire families that have been affected by sexual abuse, including young people with inappropriate sexual behaviours, adult male and female sexual abusers, victims of abuse and other family members. For more information, see www.lucyfaithfull.org.uk. 


\section{Stage 1: The initial case file analysis}

Analysis by the CATS research team of data held in case files provided by Norfolk Constabulary (41 files), the Metropolitan Police Service (four files) and the Lucy Faithfull Foundation (22 files) to create an initial draft typology.

The police forces and the LFF were asked to provide relevant case files according to a set of criteria provided by the CATS research team. The case files were accessed by the research team at the three sites and relevant data was extracted. The subsequent analysis used an inductive approach, which involved grouping together similar words emerging from the files so that overarching terms or concepts could be created for the typology template; it resulted in the identification of 26 'contextual factors' of offending, such as the relationship of the perpetrator to the victim and the location where the offence(s) had occurred.

The typology template with the 26 contextual factors was then applied to the same case files, enabling the research team to group together files with similar characteristics. This grouping led to the development of nine initial types, listed in Table A1: Initial draft typology at the end of Stage 1.

\section{Table A1: Initial draft typology at the end of Stage 1}

\section{Type}

Type 1: Opportunistic familial abuse/control

Type 2: Lone with material incentives

Type 3: Prolific informal online with material incentives

Type 4: Authority figure

Type 5: Multiple online identities and indecent image collection

Type 6: Predatory organised and networked

\section{Type 7: Technology savvy}

Type 8: Lone targeted coercive online control

Type 9: Caregiver and indecent image production

\section{Description}

Relies upon proximity to children, either in their own home or in the neighbourhood.

Usually though online access to children, via teenagebased chatrooms or smartphone applications.

Involves sexual communication, potentially grooming victims for the production of CSA material.

Involves exploitation of an imbalance of power between the perpetrator and the victim.

Involves using different identities to seek and engage with victims, mainly online.

Organised networks with multiple perpetrators operating locally, nationally and internationally.

Involves using multiple platforms with multiple devices to engage with multiple victims.

Offending is solo but organised and involves identifying and targeting victim(s).

CSA material is created by the victim's mother or maternal caregiver, who may be controlled by a male perpetrator. 


\section{Stage 2: Initial testing of the typology}

Testing and refining of the initial draft typology by CATS, through the analysis of case files from the Metropolitan Police Service (30 files), West Yorkshire Police (30 files) and Sussex Police (30 files); a series of focus groups with professionals from statutory and voluntary sector organisations across England and Wales; and a review by Professor Michael Seto of the work to date.

Analysis of data from a further 90 case files was carried out by the CATS research team to test the initial draft typology. This involved attempting to match the abuse described in each of the new files to one of the types developed during Stage 1. Cases with an uncertain fit - such as those on the boundary between two types and/ or complex cases - and those where there was no fit with the types in the typology were highlighted for further discussion.

Alongside this analysis, the research team ran a series of 10 focus groups involving professionals engaged in work with perpetrators and victims of CSA. The aim was to strengthen the development of the typology by exploring the typology's appropriateness, utility and wider implications, and to provide additional perspectives and insights that might otherwise have been missed.

\section{Table A2: Locations of focus groups}

\begin{tabular}{|l|l|}
\hline Location & No. of groups \\
\hline Cardiff & 2 \\
\hline Bristol & 1 \\
\hline Epsom & 1 \\
\hline London & 2 \\
\hline Norfolk & 1 \\
\hline Sheffield & 1 \\
\hline Sussex & 2 \\
\hline Total & 10 \\
\hline
\end{tabular}

In setting up the focus groups, the research team sought to identify organisations and individuals with direct knowledge of tackling or responding to CSA across England and Wales. They brought together 48 professionals from a range of backgrounds, including academics, probation officers, police officers, policymakers, researchers, medical doctors, psychiatrists, psychologists, support workers from both victim-facing and offender-facing organisations, and technology experts.

In each focus group, the research team presented the initial draft of the typology and asked participants for their views on the relevance of each of the nine types to their own experiences. Following a group discussion, participants were asked for overarching thoughts, concerns and suggestions regarding the typology. The focus groups lasted between 45 and 150 minutes, allowing for debate and ensuring that all participants were able to contribute.

The focus groups were audio recorded, with the participants' permission, and transcribed verbatim. Analysis of this material highlighted a number of points requiring further reflection and revision:

- Type 1: Opportunistic familial abuse/ control. While participants largely recognised the intra-familial type, they felt that opportunistic was not reflective of the main characteristics of this type, as many perpetrators will regularly plan their abuse. They also suggested that this category should include abuse by perpetrators unrelated to the victim but in close proximity to the family.

- Type 2: Lone with material incentives. Many participants recognised this type from their own practice, although some felt it lacked distinctiveness. It was suggested that this type typically involved online offending, and should be broken down and its features used to define a new set of online types.

- Type 3: Prolific informal online with material incentives. There were opposing views about the validity and generalisability of this type; participants suggested that it should be broken down to inform a type of online offending. 
- Type 4: Authority figure. Overall, this was considered an accurate description of an offending type, but participants also highlighted similarities between this and Type 1 - specifically around issues and degrees of authority and coercion.

- Type 5: Multiple online identities and indecent image collection. Participants recognised many elements of this type, but it was felt to need some clarification.

- Type 6: Predatory organised and networked. There was some opposition to certain semantic elements within the description of this type, such as use of the word 'predatory'. However, it was seen by most participants as useful and applicable for practitioners dealing with cases of CSE.

- Type 7: Technology savvy. This type was clearly recognised by participants, albeit with caveats. For instance, while the focus on technology was familiar, it was felt that the definition needed to be clearer, as the type appeared similar to others.
- Type 8: Lone targeted coercive online control. The majority of participants had not encountered cases resembling this type, and it was felt that the type should be included as a subtype within other online offending types rather than a distinct type in itself.

- Type 9: Caregiver and indecent image production. Some participants welcomed a distinct category for female perpetrators who commit CSE/CSA, but the gendered element was challenged by others.

Feedback highlighted the importance of showing that vulnerable individuals can be targeted by perpetrators for access to their children or those under their care.

Additionally, a review of the work undertaken in Stages 1 and 2 was carried out by Professor Michael Seto. ${ }^{10}$ In light of his feedback, the issues raised by the focus groups and the findings from analysis of the 90 additional case files, a revised draft typology was produced (see Table A3).

Table A3: Revised draft typology at the end of Stage 2

\section{Initial draft typology (Stage 1)}

Type 1: Opportunistic familial abuse/ control

\section{Type 2: Lone with material incentives}

Type 3: Prolific informal online with material incentives

Type 5: Multiple online identities and indecent image collection

Type 7: Technology savvy

Type 8: Lone targeted coercive online control

\section{Type 4: Authority figure}

Type 6: Predatory organised and networked

Type 9: Caregiver and indecent image production

\section{Revisions}

The type was renamed and amended to include perpetration by individuals in close proximity to the family.

These types were merged with other online types to create new online types.

This type was retained.

The type was separated into 'group-based' and 'commercial'.

The gendered element was removed from this type.
Revised draft typology

Intra-familial

Online communication/ grooming

Online collection and distribution

Authority figure

Group-based

Commercial

Exploitation by proxy

10 Professor Seto is Director of Forensic Rehabilitation Research, Integrated Forensic Program, Royal Ottawa Health Care Group and Associate Professor, Department of Psychiatry, University of Toronto. He has published extensively on child sexual offending and regularly presents at scientific meetings and professional workshops. 


\section{Stage 3: Further testing of the typology}

Further testing and refining of the draft typology by the CSA Centre's research team, through the analysis of a set of 572 case files from Saint Mary's SARC.

In order to extend the range of CSA contexts in which the draft typology had been tested, the CSA Centre's Research Team carried out further testing on a dataset, belonging to Saint Mary's SARC, which had previously been anonymised and analysed in connection with a separate study (Karsna and Majeed-Ariss, 2019). In creating the original dataset, Saint Mary's SARC had collected data from 986 paper case files into an Excel spreadsheet; besides background and demographic data about the SARC's 'service users', the information covered the route by which they had been referred to the SARC, the nature of the abuse reported to have taken place, and the people suspected of committing it. The choice of data extracted was informed by the 'data collection template', a core dataset developed by the CSA Centre to standardise and improve agencies' recording of data about CSA (Karsna, 2019).

It should be recognised that the data was collected from a service providing forensic medical examinations: the children and young people attending the SARC had all reported or been suspected of experiencing contact sexual abuse, most commonly penetrative. Notwithstanding that limitation, this was a large dataset, containing information on a range of contextual factors related to the abuse, on which the typology could be tested in order to consider its applicability in a different context.

In order to reflect the focus of the typology, only the 572 cases that related to offending by adults were included in the analysis. Each of these cases was studied using the contextual factors developed during Stages 1 and 2 of the typology's development (e.g. location, number of perpetrators, connection between perpetrator and victim) and allocated to a type, or multiple types, in the typology.
Cases were initially categorised by looking at the connection between perpetrator and victim, as this provided a means of sorting the cases into the more obvious types (such as 'CSA with the family environment' and 'CSA through trusted relationships outside the family environment'). However, other contextual factors were also taken into account to ensure that the offending did not fit better within another type (e.g. where the perpetrator might be an intermediary for another perpetrator, or where multiple perpetrators were involved). Additionally, the brief case notes that were associated with some files were reviewed.

None of the analysis of the data was quantitative; the testing took place solely to establish whether cases could be allocated to types - and, where they could not, whether there were any common factors between such cases that suggested a new type.

This exercise was moderated, with two researchers conducting the analysis separately and then comparing, discussing and agreeing the final allocation of cases to types. In the $20 \%$ of cases where the reviewers did not initially agree on their allocation to a type, they met to reach a common understanding.

The testing resulted in a good overall 'fit' between the cases in the dataset and the types defined in the typology, but it revealed that the typology needed to be expanded to cover two very different forms of offending - involving situations where the perpetrator established a social contact with the victim (either online or face-to-face), and where the perpetrator had no previous connection with the victim and abducted/attacked them. Accordingly, two types were added: 'CSA through a personal connection' and 'CSA through attack by an unknown person'. 


\section{Stage 4: Review by sector experts}

Final review and editing of the draft typology, led by the CSA Centre's research team, involving workshops, discussions and written feedback from sector experts.

The final part of the typology's development involved a review process, led by the CSA Centre, with sector experts. These experts were selected on the basis that they would offer perspectives that might not have emerged in the previous focus groups with practitioners. The review involved:

- a discussion meeting with nine staff from across strategic, analysis and operational teams at the National Crime Agency (NCA)

- a workshop with 18 practitioners and researchers at a conference hosted by the National Organisation for the Treatment of Abusers (NOTA), a national support organisation for professionals

- two workshops with 38 practitioners at the Rape Crisis England \& Wales (RCEW) annual conference, bringing together staff and volunteers from Rape Crisis Centres from across the UK and other professionals in the field

- a workshop with 11 of the CSA Centre's staff members, from a range of professional backgrounds including social work, policy, research and police.

The NCA was consulted because it had been recognised from the outset of the study that the nature of crimes dealt with by local police forces and by the NCA differ. Although it was not feasible to conduct a full review of NCA cases, it was considered important to consider how well the typology would fit with the kinds of offences seen by the NCA. The NOTA and RCEW conferences presented opportunities to share the draft typology with a different group of practitioners and researchers from those who had been involved in the Stage 2 focus groups. Similarly, reviewing the draft typology with members of staff at the CSA Centre provided a further opportunity to involve a group of professionals with expertise across the CSA field.
The draft typology was presented to these groups for their comment, either in summary written form or through a presentation. Where a workshop approach was feasible (CSA Centre staff, NOTA and RCEW conferences), the presentation was accompanied by group work, in which each group discussed two or three of the types in more detail. Detailed notes taken at the workshops were thematically analysed, along with the participants' feedback, to identify areas where the typology could be strengthened.

This review stage highlighted a number of points to be taken into account, and some potential future refinements to the new typology.

For example, it was suggested that there were some additional types of CSA offending that had not been identified through the initial case file review and focus groups. In particular, NCA staff questioned the lack of a distinct transnational type, and highlighted the growing prevalence in their own work of cases which feature offending outside the UK by British nationals. Although transnational offending had been discussed in the Stage 2 focus groups, it had been felt that there was insufficient evidence in the data to include this as a distinct type. The NCA provided examples of such offending, but these fitted existing types within the typology, with the overseas element featuring in but not defining the offending. Consequently, we amended the description of those types in the typology presented here - for example, the description of CSA through trusted relationships now recognises that this abuse happens overseas as well as in the UK. However, we recognise that transnational offending has not been studied in depth during the development of this typology, and that more distinct context and dynamics may become apparent following detailed examination of a larger number of cases with a transnational element. We therefore recommend that further work is undertaken in this area to build on this initial typology in the future.

In addition, a number of reviewers felt that labelling the different types with numbers ('type 1', 'type 2' etc.), which had been done for clarity and ease of reference, inadvertently implied ordering by the seriousness of the offending. This had not been the intention; accordingly, it was decided to remove the numbering of the types, and to make a number of further revisions to the typology titles, as shown in Figure 2 on page 11. 


\section{References}

Beckett, H. and Walker, J. (2017) Words matter: Reconceptualising the conceptualisation of child sexual exploitation. In Beckett, $\mathrm{H}$. and Pearce, J. (eds.) Understanding and Responding to Child Sexual Exploitation, Abingdon: Routledge.

CSA Centre (2018) Child Sexual Exploitation Perpetrators Research Programme Briefing. Barkingside: CSA Centre.

Department for Education (2018). Working Together to Safeguard Children: A Guide to Inter-agency Working to Safeguard and Promote the Welfare of Children. London: DfE.

Glaser, B. and Strauss, A. (1967) The Discovery of Grounded Theory: Strategies for Qualitative Research. New York: Aldine de Gruyter.

Karsna, K. (2019) Improving Your Data on Child Sexual Abuse: A Practical Guide for Organisations. Barkingside: CSA Centre.

Karsna, K. and Majeed-Ariss, R. (2019) Characteristics and Experiences of Children and Young People Attending Saint Mary's Sexual Assault Referral Centre, Greater Manchester: A Review of 986 Case Files. Barkingside: CSA Centre.

Office for National Statistics (2020) Child Sexual Abuse in England and Wales: Year Ending March 2019. Titchfield: ONS.

Pascoe, P. and Sharples, E. (2020) Developing a Typology of Child Sexual Abuse Offending: A Rapid Review of Methods Used in Empirical Studies. Barkingside: CSA Centre. 
Centre of

expertise

on child

sexual abuse

Barnardo House, Tanners Lane, Barkingside, Ilford, Essex IG6 1QG

E: info@csacentre | @csacentre 